\title{
Analisis Perbandingan Metode Neural Network Dan K - Nearest Neighbor Dalam Pemanfaatan Kembali Jasa Rawat Inap Pada Rumah Sakit Umum
}

\author{
Abdul Ibrahim *1, Rachmat ${ }^{2}$ \\ ${ }^{1,2}$ Manajemen Informatika, Teknik Informatika; Streat Perintis Kemerdekaan Km.9, \\ Streat Sultan Alauddin No.250. \\ ${ }^{3}$ Program Studi Manajemen Informatika, STMIK Dipanegara, Makassar \\ ${ }^{4}$ Program Studi Teknik Informatika, POLITEKNIK LP3I, Makassar \\ e-mail: *11 abdulibrahim@dipanegara.ac.id,${ }^{2}$ rachmat27udinus@gmail.com
}

\begin{abstract}
Abstrak
Berdasarkan penelitian diatas penulis menyarankan menggunakan metode optimasi Particall Swarm Optimization (PSO) sehingga akurasi yang didapat lebih baik dari penelitian ini Penyesuaian jumlah populasi dapat memberikan optimasi yang lebih baik, tetapi diikuti dengan penambahan waktu komputasi. Sehingga dapat akurasi yang akan didapatkan jauh lebih tinggi dibandingkan dengan metode yang sekarang ini. Penambahan metode PSO ini diharapakan juga bisa membantu dalam peneliti dibidang datamining ini.NN dan k-NN merupakan salah satu algoritma untuk regresi maupun klasifikasi sudah secara sukses diimplementasikan di berbagai bidang Pada penelitian ini bertujuan mengembangkan model prediksi dengan menggabungkan algoritma $\mathrm{NN}$ dan k-NN dengan metode seleksi atribut dimana menggunakan metode $\mathrm{NN} \mathrm{k}=10$ didapat akurasi $25,00 \%$ sedangkan dengan menggunakan metode k-NN k = 10 akurasi 15,00\% dan Precission NN sebesar 12,50\%, Precission k-NN sebesar $10,00 \%$, recall $\mathrm{NN}$ sebesar $11,11 \%$ sama dengan recall $\mathrm{k}-\mathrm{NN}$ sebesar $11,11 \%$.
\end{abstract}

Kata Kunci :, Neural Network (NN), K- Nearst Neighbor (K-NN), Klasifikasi, Pasien, Pemanfaatan

\begin{abstract}
Based on the above research the authors suggest using particall swarm optimization (PSO) optimization method so that the accuracy obtained better from this study Population number adjustment can provide better optimization, but followed by the addition of computing time. So that the accuracy that will be obtained is much higher compared to the current method. The addition of this PSO method is also expected to help in researchers in the field of datamining.NN and $k-N N$ are one of the algorithms for regression and classification has been successfully implemented in various fields In this study aims to develop a prediction model by combining $n n$ and $k$-NN algorithms with attribute selection methods where using NN method $k$ $=10$ obtained accuracy of $25.00 \%$ while by using the method $k-N N k=10$ accuracy $15.00 \%$ and Precission NN by $12.50 \%$, Precission $k-N N$ by $10.00 \%$, NN recall by $11.11 \%$ equal to recall $k-N N$ of $11.11 \%$.
\end{abstract}

Keywords :, Neural Network (NN), K- Nearst Neighbor (K-NN), Classification, Patient, Utilization

\section{PENDAHULUAN}

Pemanfaatan jasa rawat inap yang merupakan hal yang paling penting dalam rumah sakit karena dengan menggunakan peramalan rumah sakit dapat memprediksi berapa banyak pasien yang akan kembali dan pada akhirnya berpengaruh terhadap kelangsungan perkembangan rumah sakit itu sendiri tidak terlepas dari interaksi tiga unsur pokok yaitu pelanggan, petugas 
pelayanan dan manajemen. Karena interaksi tersebut, timbul output dari suatu proses penyampaian jasa berupa pelayanan yang akan dinilai kembali oleh pelanggan sebagai suatu pelayanan yang bermutu dan memuaskan[1].

Memahami kebutuhan pasien adalah merupakan hal penting yang mempengaruhi kepuasan pasien. Pasien yang puas merupakan asset yang sangat berharga, karena dengan kepuasan pasien maka akan memberikan informasi kepada orang-orang dekatnya (saudara, keluarga dan tentangga), bahwa pelayanan yang diberikan oleh pihak rumah sakit umum DR. Wahidin Sudirohusodo sangat memuaskan. Rumah sakit sebagai unit pelayanan rujukan dari unit pelayanan kesehatan dibawahnya seperti : puskesmas, praktek dokter pribadi, apotek dan lain-lain, juga merupakan bagian keluaran dari pelayanan Rumah sakit yang dituntut untuk membina kerjasama yang baik dan saling menguntungkan dengan mengutamakan kepuasan pasien[2].

Dengan menggunakan Metode Neural Network (NN) dan Metode $K$ - Nearest Neighbor $(k-N N)$ maka kita dapat memperkirakan jumlah pasien yang akan kembali ke rumah sakit. Rumah sakit sebagai unit pelayanan rujukan dari unit pelayanan kesehatan dibawahnya seperti: puskesmas, praktek dokter pribadi, apotek dan lain-lain, juga merupakan bagian keluaran dari pelayanan Rumah sakit yang dituntut untuk membina kerjasama yang baik dan saling menguntungkan dengan mengutamakan kepuasan pasien[3].

Apabila pelanggan memilih rumah sakit yang berkualitas, maka faktor utama yang mempengaruhi pemilihannya adalah pelayanan petugas. Mereka akan memilih rumah sakit yang menurutnya dapat memberikan pelayanan yang terbaik. Seorang penderita dapat menilai pelayanan suatu rumah sakit, meski kadang-kadang sulit menilai secara akurat perawatan dan teknik keperawatan yang diberikan kepadanya[4].

Arvianto Candra dkk telah membandingan algoritma Neural Network (NN) dan $k$ Nearest Neighbor $(k-N N)$ pada pemanfaatan jasa rawat inap. Neural Network $(N N)$ dan $K$ Nearest Network $(k-N N)$ sangat dikenal dikarenakan memiliki kesederhanaan dan kemampuan dalam memodelkan beragam masalah di berbagai bidang. Muhammad Ilyas Sikki k-NN memiliki kelebihan antara lain yaitu ketangguhan terhadap training data yang memiliki banyak noise dan efektif pabila training datanya besar, proses mudah dire presentasikan dibandingkan dengan metode lain. Dan penelitian yang dilakukan oleh Neneng Sunengsih[5].

\section{METODE PENELITIAN}

\subsection{Jenis Penelitian}

Jenis penelitian yang dilakukan adalah dengan metode eksperimen, yaitu untuk mengetahui pengaruh metode Neural Network (NN) dan K-Nearest Neighbor (k-NN) dalam menghasilkan nilai RMSE yang lebih baik, dilakukan sebuah pengujian dengan sebuah data kemudian diimplementasikan pada rapidminer dan membandingkan pengujian data dengan tanpa menggunakan metode optimasi.

\subsection{Metode Pengumpulan Data}

Berdasarkan sumbernya, data penelitian dibagi menjadi 2 jenis, yaitu data primer dan data sekunder. Data primer merupakan data yang diperoleh dengan cara mencari dan mengumpulkannya sendiri data yang dibutuhkan, biasanya data primer dapat diperoleh dengan cara wawancara, observasi ataupun menyebarkan kuesioner, sedangkan data sekunder diperoleh dari sumber yang sudah ada, misalnya data yang diperoleh dari perusahaan. Untuk penelitian ini, data yang digunakan adalah data sekunder, yaitu 
data yang diperoleh dari Rumah sakit DR. Wahidin Sudiruhusodo Makassar dapat ditunjukkan pada Tabel 1 dibawah ini :

Tabel 2.2 Tahun 2009 sampai Tahun 2011

\begin{tabular}{|c|c|c|c|c|c|c|}
\hline No. & $\mathbf{x 1}$ & $\mathbf{x 2}$ & $\mathbf{x 3}$ & $\mathbf{x 4}$ & $\mathbf{x 5}$ & $\mathbf{y}$ \\
\hline 1 & 7 & 5 & 3 & 3 & 3 & 1 \\
\hline 2 & 2 & 2 & 2 & 2 & 2 & 0 \\
\hline 3 & 4 & 0 & 4 & 0 & 0 & 0 \\
\hline 4 & 4 & 1 & 2 & 0 & 0 & 1 \\
\hline 5 & 3 & 1 & 1 & 1 & 1 & 0 \\
\hline 6 & 2 & 6 & 14 & 2 & 2 & 1 \\
\hline 7 & 8 & 1 & 10 & 4 & 4 & 1 \\
\hline 8 & 9 & 6 & 3 & 5 & 5 & 0 \\
\hline 9 & 3 & 1 & 1 & 1 & 1 & 1 \\
\hline 10 & 2 & 3 & 8 & 2 & 2 & 1 \\
\hline
\end{tabular}

Dimana:

$\mathrm{Y}=$ Minat memanfaatkan kembali jasa rawat inap

$\mathrm{X} 1=$ Fasilitas medis dan obat ( Availability $)$

X2 = Daya tanggap ( Responsiveness $)$

X3 = Kehandalan dan akurasi ( Reliability )

$\mathrm{X} 4$ = Jaminan ( Assurance )

X5 = Kepedulian ( Empaty )

\subsection{Metode Penyelesaian yang diusulkan}

Dalam melakukan prediksi terhadap pasien terhadap pemanfaatan kembali jasa rawat inap diperlukan metode Neural Network $(N N)$ dan $K$-Nearest Neighbor $(k-N N)$ yang diusulkan untuk selanjutnya digunakan dalam menentukan parameter dari arsitektur jaringan yang akan digunakan untuk pembelajaran. Dengan kedua metode diatas yang digunakan diharapkan ada satu metode yang terbaik untuk penelitian ini.

\subsection{Eksperimen dan Pengujian Metode}

Sebelum melakukan pengujian, data yang sudah diperoleh dilakukan preprocessing data. Preprocessing data yang dilakukan pada penelitian ini menggunakan normalisasi data. Normalisasi data digunakan untuk mengelompokkan data ke dalam skala atau jangkauan tertentu sehingga mempermudah dalam mengolah data. Normalisasi data pada penelitian ini menggunakan normalisasi data dalam jangkauan [0,1]. Preprocessing data dilakukan terlebih dahulu menggunakan Microsoft Excel. Untuk menghitung normalisasi data dalam jangkauan [0,1] dapat ditunjukkan pada persamaan (3.1) dan hasil dari normalisasi data terdapat pada tabel 3.2 dibawah ini

$$
\hat{x}_{i k}=\frac{x_{i k}-\min \left(x_{k}\right)}{\max \left(x_{k}\right)-\min \left(x_{k}\right)}
$$


Tabel 2.4 Hasil Normalisasi Data

\begin{tabular}{|c|c|c|c|c|c|c|}
\hline $\mathrm{A}$ & $\mathrm{B}$ & $\mathrm{C}$ & $\mathrm{D}$ & $\mathrm{E}$ & $\mathrm{F}$ & $\mathrm{G}$ \\
\hline 1 & 5.00 & 1.00 & 5.00 & 1.00 & 1.00 & 1.00 \\
\hline 2 & 6.00 & 3.00 & 0.00 & 2.00 & 2.00 & 0.00 \\
\hline 3 & 3.00 & 1.00 & 1.00 & 1.00 & 1.00 & 1.00 \\
\hline 4 & 2.00 & 4.00 & 10.00 & 2.00 & 2.00 & 0.00 \\
\hline 5 & 6.00 & 2.00 & 2.00 & 2.00 & 2.00 & 0.00 \\
\hline 6 & 4.00 & 1.00 & 4.00 & 0.00 & 0.00 & 1.00 \\
\hline 7 & 5.00 & 2.00 & 1.00 & 1.00 & 1.00 & 1.00 \\
\hline 8 & 3.00 & 1.00 & 3.00 & 1.00 & 1.00 & 0.00 \\
\hline 9 & 4.00 & 2.00 & 0.00 & 0.00 & 0.00 & 0.00 \\
\hline 10 & 2.00 & 2.00 & 2.00 & 2.00 & 2.00 & 1.00 \\
\hline
\end{tabular}

\subsection{Penelitian Terkait}

Data mining merupakan metode untuk menganalisis data dengan jumlah yang banyak untuk mengetahui hubungan yang tidak terduga dalam data dan merangkumnya menjadi informasi baru sehingga mudah dipahami dan berguna bagi pemilik. Pelanggan harus mengenali karakteristik dari suatu produk atas jasa agar pelanggan mampu merasakan atau menilai bahwa produk atau jasa yang diberikan sesuai apa yang mereka beli dengan yang mereka terima. Penilaian dapat didefensikan sebagai hubungan antara apa yang mereka ingin tukarkan dengan apa yang mereka terima walaupun hal ini seringkali dinyatakan sebagai kesenjangan antara harga dan kualitas[6].

\subsection{Seleksi Atribut}

Alpha untuk masukkan merupakan nilai yang menentukan apakah salah satu prediktor yang saat ini tidak dalam model, harus ditambahkan ke model. Nilai P dari masing- masing prediktor dalam model ini tidak dibandingkan dengan tingkat ini, jika nilai $\mathrm{P}$ dari prediktor kurang dari tingkat, sehingga prediktor merupakan kandidat untuk dimasukkan ke dalam model. Korelasi sederhana dapat ditentukan dengan menggunakan matriks tabel korelasi sederhana. Prosedur ini akan berakhir ketika semua variabel yang masuk ke dalam model dan memiliki nilai P kurang dari Alpha tertentu untuk masukan[7].

\subsection{Neural Network (NN)}

Neural Network merupakan sebuah metode yang bekerja berdasarkan cara kerja otak pada manusia. Pada Gambar 1 terlihat bahwa struktur Neural Network mirip dengan otak manusia. Informasi dikirim ke neuron melalui suatu pembobotan input. Kemudian input ini diproses oleh fungsi propagation yang akan menaikkan nilai bobot input. Hasilnya kemudian dibandingkan dengaan threshold oleh fungsi aktivasi, jika input melampaui batas threshold, maka neutron diaktifkan, jika tidak maka neutron akan di inhibit.[8].

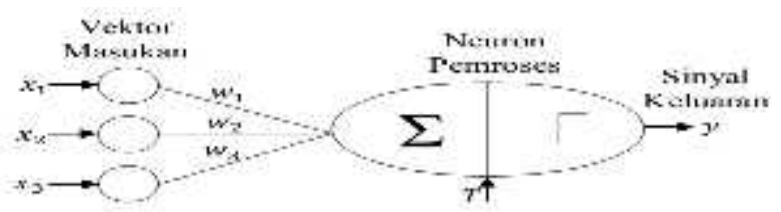

Gambar 2.7 Desain umum ANN 
Lapisan-lapisan penyusun neural network dibagi menjadi tiga, yaitu :

1. Input Layer adalah unit-unit dalam lapisan input yang disebut dengan unit-unit input yang bertugas untuk menerima pola inputan dari luar yang menggambarkan suatu permasalahan.

2. Hidden Layer adalah unit-unit dalam lapisan tersembunyi yang disebut dengan unit-unit tersembunyi, yang mana nilai output-nya tidak dapat diamati secara langsung.

3. Output Layer adalah unit-unit dalam lapisan output yang disebut dengan unitunit output, yang mana merupakan solusi neural network terhadap suatu permasalahan.

\section{8 k-Nearest Network (k-NN)}

Prinsip kerja $K$ - Nearest Neighbor $(k-N N)$ adalah mencari jarak terdekat antara data yang akan dievaluasi dengan $\mathrm{K}$ tetangga ( neighbor ) terdekatnya dalam data pelatihan. Data training diproyeksikan ke ruang berdimensi banyak, yang mana masing- masing dimensi menjelaskan fitur dari data. Ruang ini dibagi menjadi bagian -bagian berdasarkan klasifikasi data training. Sebuah titik pada ruang i ni ditandai kelas c, jika kelas c merupakan klasifikasi yang paling banyak ditemui pada $\mathrm{k}$ buah tetangga terdekat titik tersebut. Algoritma $k-N N$ tergolong dalam algoritma supervised yaitu proses pembentukan algoritma diperoleh melalui proses pembelajaran (learning) pada recordrecord lama yang sudah terklasifikasi dan hasil pembelajaran tersebut dipakai untuk mengklasifikasikan record baru dengan output yang belum diketahui. Dalam algoritma $k$ $N N$ sebuah data baru diklasifikasikan berdasarkan jarak data baru tersebut dengan tingkat kemiripan data baru terdekat terhadap data pola. Jumlah data tetangga terdekat ditentukan dan dinyatakan dengan $\mathrm{k}$. Penentuan nilai $\mathrm{k}$ terbaik dapat ditentukan dengan optimasi parameter. Jarak antara objek x dan y didefinisikan sebagai Dxy, dimana $\mathrm{x}, \mathrm{i}$ merupakan record yang akan diprediksi dan y, i merupakan record data pola sedangkan nilai $\mathrm{n}$ didefinisikan sebagai jumlah atribut dan nilai i merujuk kepada record ke-i.

\subsection{Backpropagation}

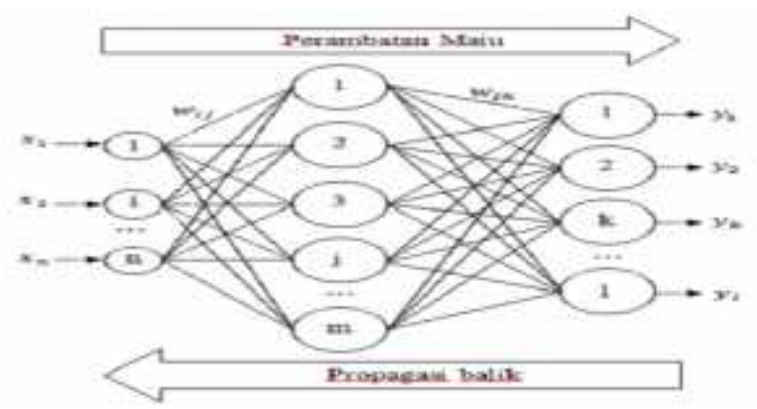

Gambar 2.9 Arsitektur ANN Backpropagation

Gambar 2 diatas merupakan contoh arsitektur ANN Backpropagation. Metode ini merupakan metode pelatihan paling popular. Cara pelatihan metode ini sama dengan Perceptron yaitu sejumlah data latih sebagai pola masukan diberikan pada jaringan kemudian dihitung pola keluaran dan jika terdapar error maka bobot dalam jaringan akan diperbarui untuk mengurangi error tersebut. Adapun langkah-langkah dari backpropagation dalam melakukan perhitungan, yaitu : 


\section{Langkah 1}

Inisialiasasi semua bobot denga bilangan random atau acak

2. Langkah 2

Jika kondisi penghentian belum terpenuhi, maka lakukan langkah 3 sampai dengan langkah 5

3. Langkah 3

Untuk setiap pasang data pelatihan, lakukan langkah 4 sampai dengan langkah 5 Fase I. Propagasi Maju (forward propagation)

4. Langkah 4

Tiap unit masukkan menerima sinyal dan meneruskan ke unit tersembunyi

5. Langkah 5

Hitung semua keluaran di unit tersembunyi (Hidden Layer)

$$
z_{n e t j}=v_{j 0}+\sum_{i=1}^{n} x_{i} v_{j i}
$$

Dimana

Vjo = bobot bias awal ke hidden layer

$\mathrm{Vji}=$ bobot awal input ke hidden layer

$\mathrm{Xi}=$ data ke-nilai

\section{HASIL DAN PEMBAHASAN}

\subsection{Proses Awal (Preprocessing)}

Proses awal sebelum dilakukan pengujian terhadap metode yang sudah diusulkan, yaitu Neural Network $(N N)$ dan $K$ - Nearest Neighbor $(k-N N)$ adalah tahap preprocessing. Tahap preprocessing yang digunakan pada penelitian ini adalah normalisasi data. Dengan menggunakan persamaan rumus (3.1), yaitu:

3)

$$
\hat{x}_{i k}=\frac{x_{i k}-\min \left(x_{k}\right)}{\max \left(x_{k}\right)-\min \left(x_{k}\right)} \quad \text { Persamaan..... }
$$

$$
\widehat{x}_{1}=\frac{57056-57056}{225084-57056}=0
$$

\subsection{Pembahasan}

Hidden 1

Node 1 (Sigmoid)

$\mathrm{x} 1: 1.859$

$\mathrm{x} 2: 0.152$

$\mathrm{x} 3: 1.432$ 
x4: -0.208

$\mathrm{x} 5:-0.225$

Bias: -1.079

Node 2 (Sigmoid)

$\mathrm{x} 1: 1.243$

$\mathrm{x} 2:-0.351$

x3: -1.813

$\mathrm{x} 4: 1.329$

$\mathrm{x} 5: 1.331$

Bias: -2.898

Node 3 (Sigmoid)

$\mathrm{x} 1: 1.938$

$\mathrm{x} 2: 0.112$

$\mathrm{x} 3: 1.537$

$\mathrm{x} 4:-0.249$

x5: -0.242

Bias: -1.125

Node 4 (Sigmoid)

$\mathrm{x} 1: 4.856$

$\mathrm{x} 2: 1.793$

$\mathrm{x} 3: 2.685$

$\mathrm{x} 4:-1.254$

x $5:-1.242$

Bias: -0.092

Node 5 (Sigmoid)

$\mathrm{x} 1: 2.672$

$\mathrm{x} 2:-1.742$

$\mathrm{x} 3:-4.062$

$\mathrm{x} 4: 1.682$

$\mathrm{x} 5: 1.748$

Bias: -3.845

Output

=ニニ=ニ

Class '1' (Sigmoid)

Node 1: 0.892

Node 2: -2.089

Node 3: 0.969

Node 4: 3.221

Node 5: -3.919 
Threshold: 0.002

Class '0' (Sigmoid)

Node 1: -0.890

Node 2: 2.098

Node 3: -0.997

Node 4: -3.208

Node 5: 3.910

Threshold: -0.001

Tabel 3.1 Hasil Pengujian NN

\begin{tabular}{|l|l|l|}
\hline No. & $\begin{array}{l}\text { Number of } \\
\text { Validation }\end{array}$ & Akurasi \\
\hline 1. & $\mathrm{~K}=10$ & $15,00 \%$ \\
\hline 2. & $\mathrm{~K}=5$ & $15,00 \%$ \\
\hline 3. & $\mathrm{~K}=2$ & $30,00 \%$ \\
\hline
\end{tabular}

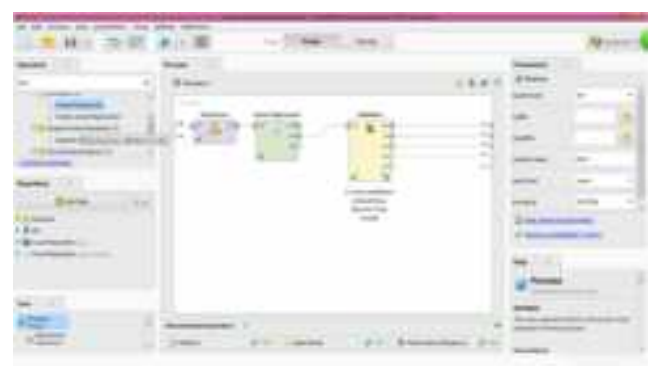

Gambar 3.1 Kernel Model k-NN
Tabel 3.2 Hasil Pengujian k-NN

\begin{tabular}{|l|l|l|}
\hline No. & $\begin{array}{l}\text { Number of } \\
\text { Validation }\end{array}$ & Akurasi \\
\hline 1. & $\mathrm{~K}=10$ & $25,00 \%$ \\
\hline 2. & $\mathrm{~K}=5$ & $25,00 \%$ \\
\hline 3. & $\mathrm{~K}=2$ & $25,00 \%$ \\
\hline
\end{tabular}

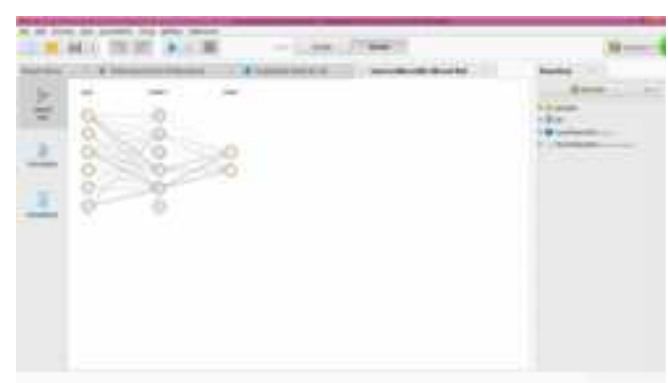

Gambar 3.2 Kernel Model Neural Network

\section{KESIMPULAN}

Klasifikasi pemanfaatan kembali jasa rawat inap menggunakan Algoritma Neural Network (NN) Dan K-Nearest Neighbor ( $k$-NN) untuk mengetahui dari algoritma mana yang paling bagus dalam klasifikasi pemanfaatan kembali jasa rawat inap pada rumah sakit DR. Wahidin Sudiruhusodo Makassar. Karena interaksi tersebut, timbul output dari suatu proses penyampaian jasa berupa pelayanan yang akan dinilai kembali oleh pelanggan sebagai suatu pelayanan yang bermutu dan memuaskan Sehingga perbandingan dari kedua algoritma ini banyak peneliti termotivasi untuk meningkatkan kinerja prediksi. bahwa pelayanan yang diberikan oleh pihak rumah sakit umum DR. Wahidin Sudirohusodo sangat memuaskan. 


\section{DAFTAR PUSTAKA}

[1] A. Info, C. Analysis, S. E. Smoothing, H. Method, and M. A. Deviation, "Comparative Analysis of Single Exponential Smoothing and Holt' s Method for Quality of Hospital Services Forecasting in General Hospital," vol. 1, no. 2, pp. 80-86, 2020, doi: 10.25008/bcsee.v1i2.8.

[2] S. Supartiningsih, "Kualitas Pelayanan Kepuasan Pasien Rumah Sakit : Kasus Pada Pasien Rawat Jalan," vol. 6, no. April, pp. 9-15, 2017, doi: 10.18196/jmmr.6122.

[3] R. Sistem, O. Nilai, K. Algoritma, and K. Spam, "JURNAL RESTI," vol. 1, no. 10, pp. 377-383, 2021.

[4] M. F. Satrianegara, "Pemanfaatan Kembali Pelayanan Kesehatan Oleh Pasien Umum Rawat Inap di Rumah Sakit Syekh Yusuf Tahun 2019," 2019.

[5] M. Nanja and purwanto, "Forward Selection Untuk Prediksi," Pseudocode, vol. 2, no. 1ISSN 2355 - 5920, pp. 53-64, 2015.

[6] P. Studi, M. Teknik, F. I. Komputer, and U. Sriwijaya, "Klasifikasi ekspresi wajah menggunakan metode principal component analysis (pca) dan convolutional neural network (cnn)," pp. 1-80, 2019.

[7] D. S. Informasi, Dengan Menggunakan Algoritma Simulated Annealing Hyper-Heuristic ( Studi Kasus : Rsia V Kendangsari Merr Surabaya) Hospital Staff Scheduling Optimization Using Simulated Annealing Hyper-Heuristic ( Case Study: Rsia Kendangsari Merr Surabaya) Algoritma Simulated Annealing Hyper-Heuristic ( Studi Kasus : Rsia Kendangsari Merr Surabaya ). 2018.

[8] M. Zufar, "Convolutional Neural Networks untuk Pengenalan Wajah Secara Real Time," vol. 5, no. 2, pp. 72-77, 2016. 